\title{
Water-Solubilization of Nucleotides-coated Single-Walled Carbon Nanotubes by High-speed Vibration Milling Technique
}

Atsushi Ikeda, ${ }^{*}$ Tomoe Hamano, Kentaro Hayashi, and Jun-ichi Kikuchi

Graduate School of Materials Science, Nara Institute of Science and Technology, Ikoma, Nara 630-0192, Japan

\section{Supporting Materials}

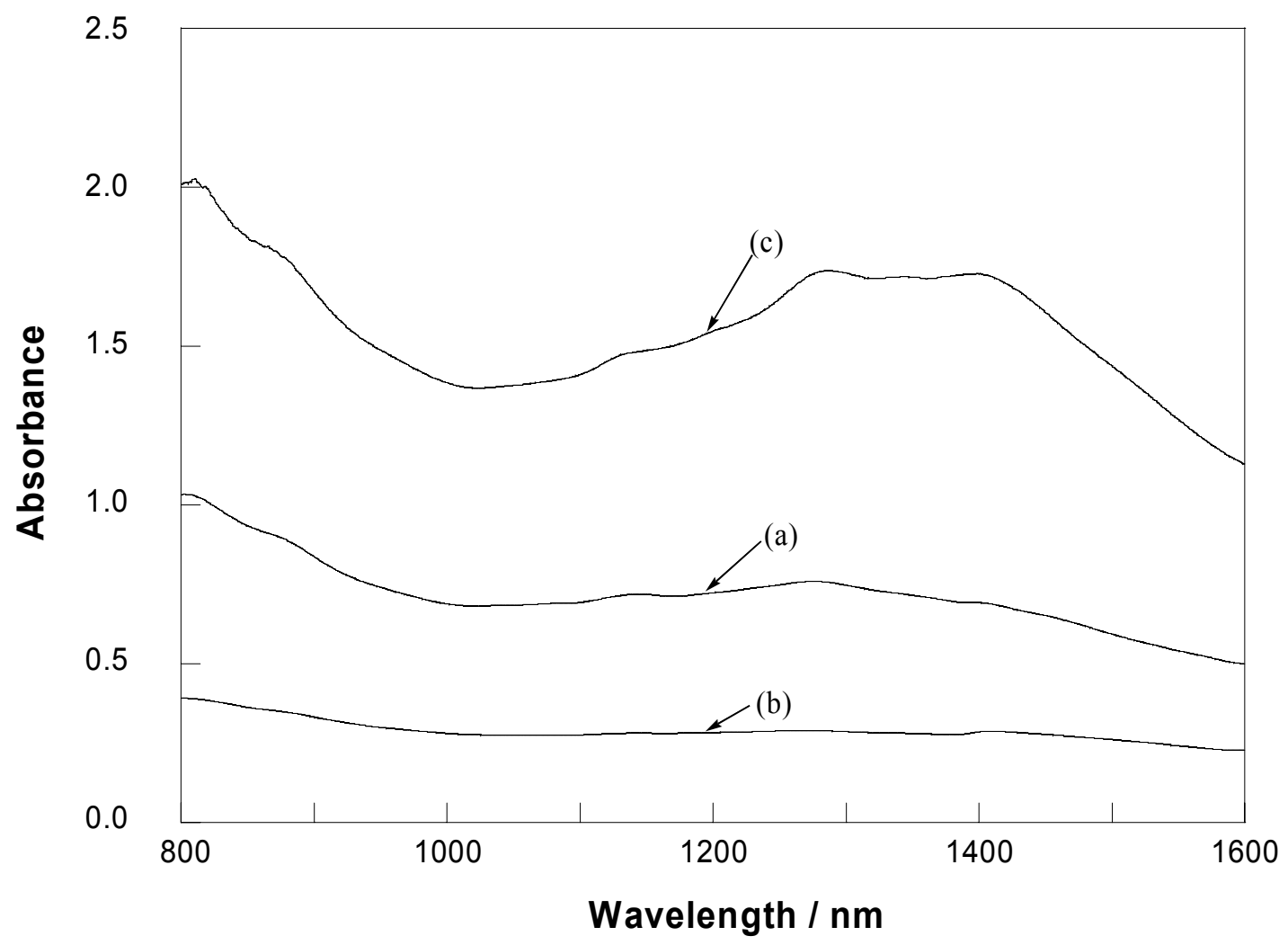

Figure S1. Near-IR spectra for (a) the SWNTs·ADP complex, (b) the SWNTs·ATP complex, and (c) the SWNTs·GMP complex in an aqueous solution. 


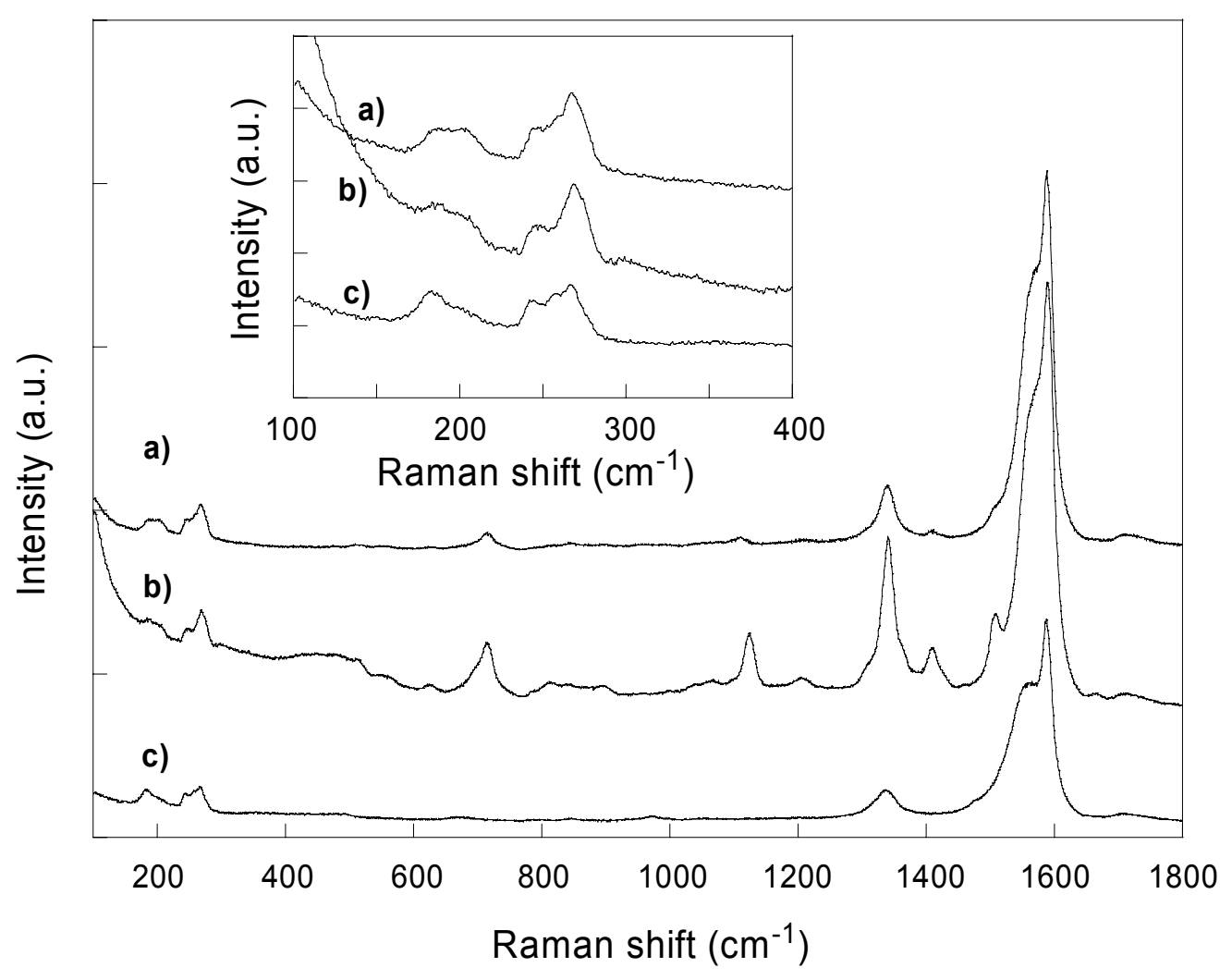

Figure S2. Raman spectra taken at $633 \mathrm{~nm}$ for (a) the SWNTs-ADP complex, (b) the SWNTs·ATP complex, and (c) the SWNTs.GMP complex in an aqueous solution. 

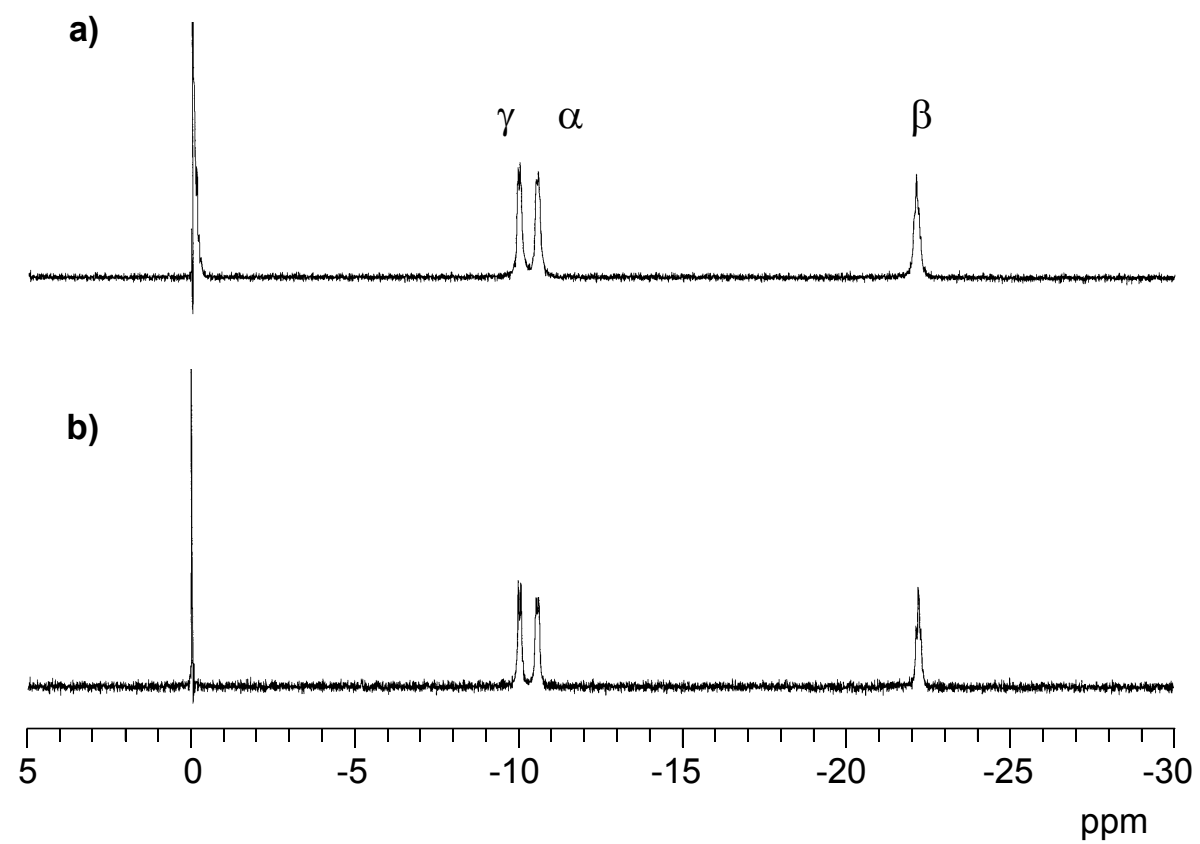

Figure S3. ${ }^{31} \mathrm{P}$ NMR spectra of (a) ATP and (b) the SWNTs·ATP complex in $\mathrm{D}_{2} \mathrm{O}$ at $25^{\circ} \mathrm{C}$. 


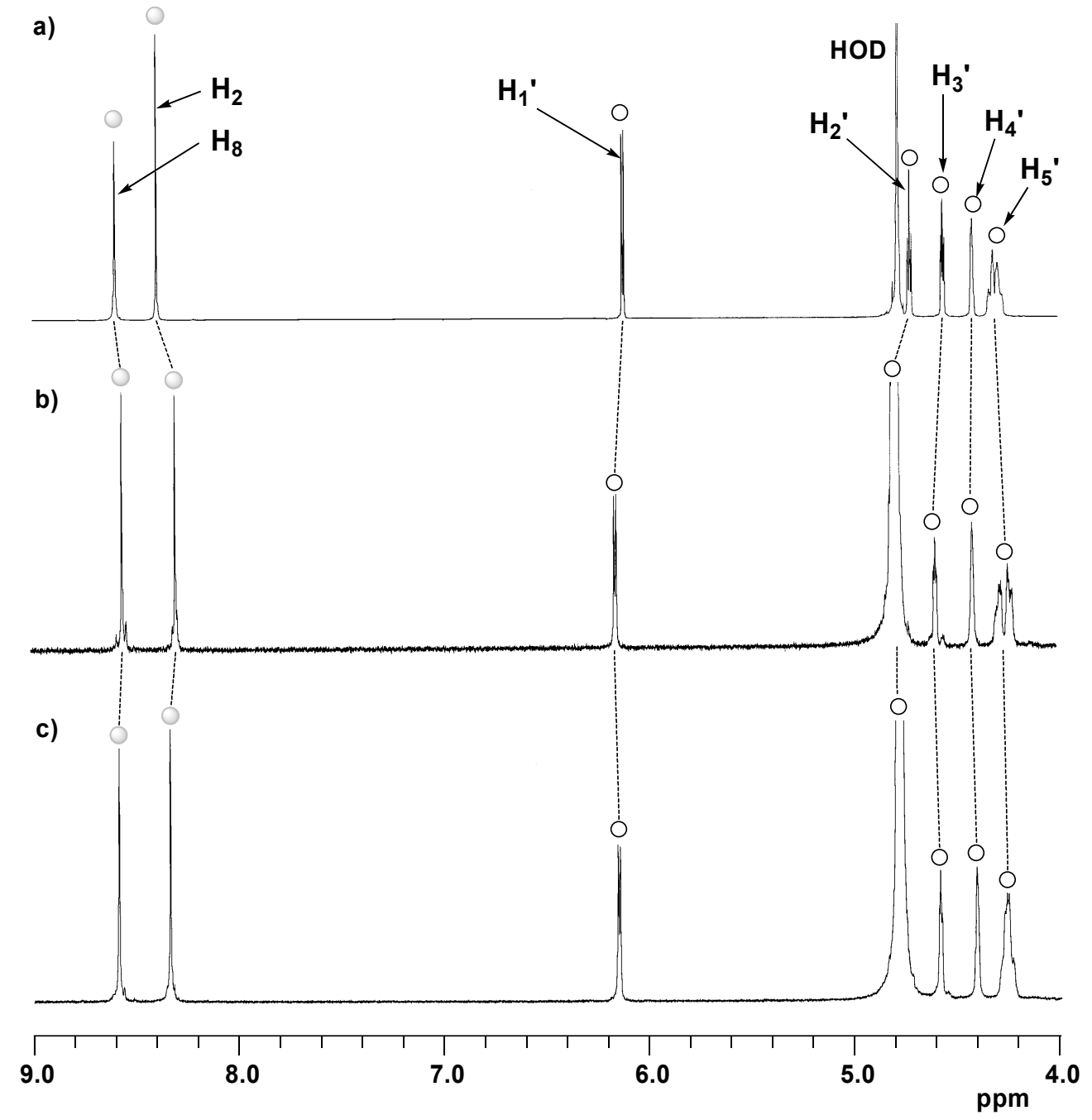

Figure S4. ${ }^{1} \mathrm{H}$ NMR spectra of (a) ATP, (b) the SWNTs-ATP complex, and (c) the SWNTs-ATP complex after the further addition of ATP in $\mathrm{D}_{2} \mathrm{O}$ at $25^{\circ} \mathrm{C}$. 